床反カと人体モデルに基づいた装着型歩行支援システム*

$$
\begin{gathered}
\text { 中 村 尚 彦*1, 齋 藤 和 成*2 } \\
\text { 王志 東*1, 小 菅一 } \text { 弘 }^{* 1}
\end{gathered}
$$

\title{
Wearable Walking Support System Based on GRF and Human Model
}

\author{
Takahiko NAKAMURA*3, Kazunari SAITO, \\ ZhiDong WANG and Kazuhiro KOSUGE \\ ${ }^{* 3}$ Department of Bioengineering and Robotics, Tohoku University, \\ 6-6-01 Aramaki-Aoba, Aoba-ward, Sendai-shi, Miyagi, 980-8579 Japan
}

\begin{abstract}
In this paper, we propose a new algorithm, referred to as the Model-based control algorithm for Anti-Gravity Muscles Assist with Ground Reaction Force feedback, to control a wearable waking support system. In this algorithm, the joint support moment of human is calculated based on the term of the antigravity and the ground reaction force of necessary joint moment of human, which is estimated based on the dynamics of a human approximated model. The algorithm is implemented in a wearable walking support device, referred to as Wearable Walking Helper-II and experimental results illustrate the potential of the proposed system.
\end{abstract}

Key Words : Robot, Muscle and Skelton, Human Engineering, Wearable, Walking Support

1.はじめに

近年，日本をはじめ世界各国では，社会の急速な高 齢化が進行している. 社会の高齢化を受け, 高齢者の 自立した生活を支援するためのロボットシステムが開 発されている.これまで開発されてきた生活支援シス テムは, 主に人間の代わりにロボットが作業を行い, 使用者がそれほど体を動かさずに仕事を達成出来ると いった利点がある. しかし, これらのシステムを用い ることで身体を動かす必要性が隇少し, 寝たきりに移 行してしまうおそれがある.この寝たきりへの移行防 止に運動が非常に重要である. 最も基本的な運動の一 つに歩行がある.この歩行を行うことで体力の維持, 向上が促進され寝たきりの防止が期待できる.

老衰等の影響により歩行に困難を感じる方を対象と した杖や歩行器といった歩行補助具が普及している. 歩行補助具の使用により抗重力筋の負担が軽減され, かつバランス保持能力が向上し, 結果的に使用者が長 時間連続的に歩行可能になることが知られている.し かし, それらの歩行補助具は両手の自由が制限された り，段差や悪路というような環境にもその使用が制限 されてしまうという問題がある. そこで著者らは, 口 ボット技術を用いることで, それらの問題を解決歩行 補助システムの構築を目指し研究を行ってきた.

\footnotetext{
* 原稿受付 2005 年 6 月 20 日.

*1 正員, 東北大学大学院工学研究科( $980-8579$ 仙台市青葉 区荒巻字青葉 6-6-01).

$* 2$ 東北大学大学院工学研究科.

E-mail : nakamura@ irs.mech.tohoku.ac.jp
}

我々の目指す支援システムは，下肢に装着した支援 テバイスにより, 脚部の負担を軽減することで, 歩行 をはじめとする下肢の運動の支援を長時間連続的に 行うシステムである.これまで, 歩行補助具の使用に より抗重力筋の負担が軽減され，長時間の自立歩行が 可能となる事から, 姿勢に応じて変化する抗重力筋へ の負担を軽減するために, 装着者の姿勢に基づいて支 援関節モーメントを決定するアルゴリズム, “Modelbased control algorithm for Anti-Gravity Muscles Assist (MAGMA)"を提案してきた. また, 装着型支援デバ イス Wearable Walking Helper-Iに適用し，立脚期の抗 重力筋の負担を軽減することで, 装着者の見かけの筋 持久力が増大するという実験結果から，下肢の運動支 援への可能性を示した ${ }^{(1)}$.

本稿では, 歩行のように脚の状態が立脚/遊脚と継 続的に遷移する運動においても，連続的な支援を可 能とする装着型支援システムを構筑する. 以下, 関連 研究について述べた後に, 連続的な支援を可能とす るために, 動力学に基づき導出した関節モーメントの 重力項および床反力項に基づいて, 支援関節モーメン トを決定する支援アルゴリズム“Model-based control algorithm for Anti-Gravity Muscles Assist with Ground Reaction Force feedback (MAGMA-GRF) ” を提案す る.さらに，新たに開発した両脚用装着型支援テバ イス Wearable Walking Helper-II(W.W.Helper-II)に, MAGMA-GRFを適用し実験によりその有効性を示す. 


\section{2. 装着型支援システム}

装着型支援システムは，まず，産業面や軍事面で健 常者の力を増幅する目的で開発された。 1960 年代に 開発された Hardiman ${ }^{(2)} 1980$ 年代に開発されたエク

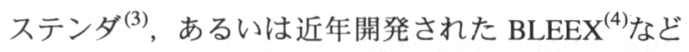
がその典型である．また我が国では，介助の現場で介 助者の負担を軽減する目的で装着型支援システムが開 発されてきた. 介護用パワーアシストスーツ(5)や腰部

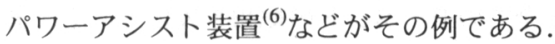

一方, 身体機能の衰えた人の運動支援を行う装着型 支援システムも開発されている. 山海らは全身に装着 して歩行支援やリハビリ支援を行う HAL 開発した (7).これは運動をタスクとフェイズに分解し, フェイ ズに応じて支援量を決定するフェイズシーケンスとい うアルゴリズムを用いて制御されており, フェイズの 判断には表面筋電位や床反力が用いられている. また, 木口らは上肢に装着して運動支援やリハビリ支援を行 う運動補助ロボットを開発した ${ }^{(8)}$ 。これは, 筋肉の活 動レベルが低い場合は手首部に発生する力を重視した 制御を行い，筋肉の活動レベルが高い場合は表面筋電 位信号によるファジィ・ニューロ制御を行っている.こ れらのシステムの多くは, 筋電信号等の生体信号に基 づき装着者の動作を推定し，支援を実現している，

生体信号に基づいて動作を推定する場合, 生体信号 は計測部位や被験者の違い, あるいは同一の被験者で あっても体調等により変化することや, 計測中の汗等 により, 計測精度が低下するといったことから, 正確 な計測は容易ではなく, また, 計測された信号はノイ ズを多く含んでいることから, 高い信号処理能力が必 要となる.さらに, 動作に基づいて支援を行う場合, 動作と支援を対応づけるデータベースが必要となるた

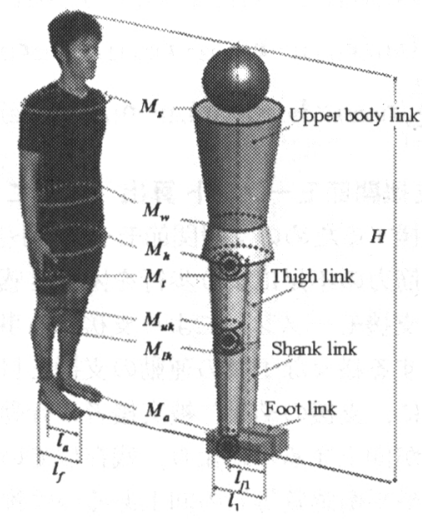

Fig. 1 Modeling a Human to Link
め, データベースにある動作しか支援できないといっ た問題や, 動作ごとに支援が異なるため, ある動作か らある動作へと動作が切り替わる際に, 支援が不連続 となりうるといつた問題がある.

\section{3. 床反力を利用した支援制御アルゴリズム}

本研究では, 長時間連続して支援が可能な装着型 システムの開発を目的としている. そのため, 生体信 号に基づいて動作を推定し, 支援を実現する事は本 研究に適さない, そこで本研究では, 生体信号や動作 推定を用いずに, 装着者が必要とする関節モーメン トを人間のモデルに基づき動力学的に推定し, 支援 関節モーメントを決定するための支援アルゴリズム “MAGMA-GRF”を提案する.

3.1 人体のモデル化 人体を図 1 に示すように, 直方体の足部リンク, 円錐台の下腿部リンクおよび大 腿部リンク，円錐台を組み合わせた胴体部之棈円体の 頭部を結合した上体部リンクからなるにモデルに近似 する. 高齢者のような歩行弱者の場合, 両腕を活発に 動かしながら歩行することは稀であるため, 本モデル では両腕も上体部リンクに含めた. その際, 各リンク の重量や長さ等のパラメータを体重や被験者の各部位 の実測値, あるいは参考文献 ${ }^{(9)} に$ 基づいて決定する事 で, 被支援者の体型に合ったリンクモデルを構築する.

また, 歩行をはじめとする下肢の運動は, 一般に矢 状平面上の運動として近似される. そこで, 各リンク をつなぐ関節は, 前額水平軸回りの回転のみ可能なヒ ンジジョイントととし, 左右の足リンクの傾き角 $\theta_{i 1}$, 足関節角度 $\theta_{i 2}$, 膝関節角度 $\theta_{i 3}$, 股関節角度 $\theta_{i 4}$ は図 2(a)に示す通りとする $(i=1,2)$. さらに, 右脚の足, 膝, 股関節 (関節 11 , 関節 12 , 関節 13 および 関節 14）が右つま先を通る矢状 $\left(O_{1}-Z_{1} X_{1}\right)$ 平面上に, ま た左脚の足, 膝, 股関節 (関節 21 , 関節 22 , 関節 23 お よび 関節 24) が常に左つま先を通る矢状 $\left(O_{2}-Z_{2} X_{2}\right)$ 平面上に常に存在するものと仮定する。

3.2 関節モーメント算出提案した人体モデル に基づき, 関節モーメントを算出する. まず, 各関節 に関節反カにーメントが, また, 足リンク (リンク 11 およびリンク 12）には外力として床反力が作用す るものとして運動方程式を導出する. リンクごとに並 進および回転についての運動方程式を導出すると, 式 が 14 個導出される.

ここで, 関節反カ/モーメントおよび床反力, さら に床反力に起因するモーメントが未知であるとする と, 未知数が 16 個となり式の数 14 よりも多くなり, “Closed Loop Ploblem ${ }^{(10),}$ としてよく知られた不静定 


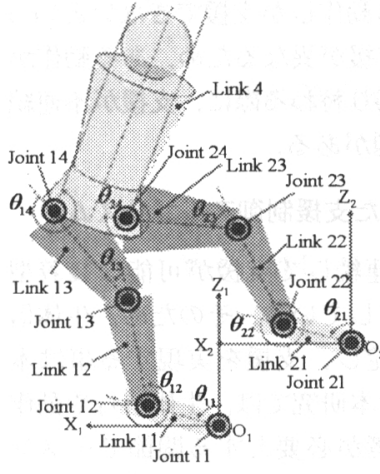

(a)

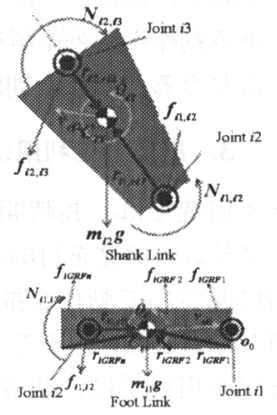

(b)
Fig. 2 (a)Simplified Model of a Human Body, (b)Free Body Diagram of Foot and Shank Link

問題となる. このため, 何らかの方法により 16 個あ る未知数のうち少なくとも 2 つを知る必要がある.

ここで脚の状態に着目する. 遊脚期には, 足に作用 する床反力および床反力に起因するモーメントが 0 と なる. そのため, 両脚が遊脚の場合, 未知数が 12 個 に減少する. また, 片脚立脚片脚遊脚の場合, 未知数 が 14 個に滅少する．そのため, どちらの場合も静定 となる.一方, 両脚立脚状態では未知数が 16 個であ り不静定である. この考察から, 床反力あるいは床反 力に起因するモーメントを何らかの方法により計測で きれば, この不静定問題が解け, かつ脚の状態が判別 できることが分かる．そこで本稿では床反力および床 反力に起因するモ一メントが計測出来ると仮定する.

以下，右膝関節モーメント $\left(N_{12,13}=\tau_{r k}\right)$ を例にと り，関節モーメント算出手順を説明する. 今, 床反力 および床反力に起因するモーメントが計測出来るもの と仮定したので, 未知数が 12 個に減少し, 未知数の 個数を式の数が上回ったので $\tau_{r k}$ の算出にはリンク 11 およびリンク 12 の運動方程式を連立させて解く方法 とリンク 13 , リンク 4 , リンク 23 , リンク 22 および リンク 21 の運動方程式を連立させる方法との 2 通り が存在する.

右膝関節モーメントを算出するので，右足に作用す る床反力を用いるのが直接的であると考え, 右膝関節 モ一メントの導出は, リンク 11 およびリンク 12 の運 動方程式を連立させて行う. 各リンクに作用する力/ モーメントは図 2(b) に示す通りであるので運動方程 式はそれぞれ，以下のようになる.

$\sum_{k=1}^{n} \mathbf{f}_{1 G R F k}-\mathbf{f}_{11,12}-m_{11} \mathbf{g}=m_{11} \dot{\mathbf{v}}_{c 11}$
$-N_{11,12}-\sum_{k=1}^{n}\left(\mathbf{r}_{1 G R F k} \times \mathbf{f}_{1 G R F k}\right)+\mathbf{r}_{11, c 11} \times \mathbf{f}_{11,12}=\frac{d \mathbf{I}_{11} \dot{\theta}_{11}}{d t}(2)$

$\mathbf{f}_{11,12}-\mathbf{f}_{12,13}-m_{12} \mathbf{g}=m_{12} \dot{\mathbf{v}}_{c 12}$

$N_{11,12}-N_{12,13}+\mathbf{r}_{12, c 12} \times \mathbf{f}_{12,13}-\mathbf{r}_{11, \mathrm{cl} 2} \times \mathbf{f}_{11,12}=\frac{d \mathbf{I}_{12} \dot{\theta}_{12}}{d t}$

ここで, $\sum_{k=1}^{n} \mathbf{f}_{1 \text { GRFk }}$ はリンク 11 に作用する全ての 床反力の総和を表し, $\sum_{k=1}^{n}\left(\mathbf{r}_{1 G R F k} \times \mathbf{f}_{1 G R F k}\right)$ は, それら に起因する全てのモーメントの総和を表している．ま た, $\mathbf{f}_{11,12}, \mathbf{f}_{12,13}$ および $N_{11,12}, N_{12,13}$ はそれぞれ関節 11 , 関節 12 に作用する反力/モーメントを表し, $m_{11}$, $m_{12}, \mathbf{I}_{11}$ および $\mathbf{I}_{12}$ はそれぞれリンク 11 , リンク 12 の 質量および慣性モーメントを表している．また， $\mathbf{v}_{c 11}$ および $\mathbf{v}_{c 12}$ はリンク 11 およびリンク 12 の重心位置 の並進速度を表し， $\dot{\mathbf{v}}_{c 11}$ および $\dot{\mathrm{v}}_{c 12}$ は $\mathbf{v}_{c 11}$ および $\mathbf{v}_{c 12}$ の時間微分を表している. また, $\mathbf{r}_{11, c 11}$ は関節 12 か ら見たリンク 11 の重心 $C_{11}$ への位置ベクトル, $\mathbf{r}_{11, c 12}$ は関節 12 から見たリンク 12 の重心 $C_{12}$ への位置ベク トル， $\mathbf{r}_{12, c 12}$ は関節 13 から見たリンク 12 の重心 $C_{12}$ への位置ベクトルを表している. また, $\dot{\theta}_{11}$ および $\dot{\theta}_{12}$ はそれぞれ $\theta_{11}$ および $\theta_{12}$ の時間微分を表している. また, $\mathbf{g}$ は重力加速度ベクトルを表している.

これらの運動方程式を連立させることで $\tau_{r k}$ を導出 する. 導出された $\tau_{r k}$ は,

$$
\tau_{r k}=\tau_{r k_{l}}+\tau_{r k_{C}}+\tau_{r k_{G}}+\tau_{r k_{G R F}}
$$

となる.ここで $\tau_{r k}$ の慣性項 $\tau_{r k_{l}}$, コリオリカ・遠心 力項 $\tau_{r k_{C}}$, 重力項 $\tau_{r k_{G}}$ および床反力項 $\tau_{k r_{G R F}}$ はそれぞ れ以下の通りとなる.

$$
\begin{aligned}
\tau_{r k_{I}}+ & \tau_{r k_{C}}=-\frac{d \mathbf{I}_{11} \dot{\theta}_{11}}{d t}-\frac{d \mathbf{I}_{12} \dot{\theta}_{12}}{d t}-m_{12} \mathbf{r}_{12, c 12} \times \dot{\mathbf{v}}_{c 12} \\
& -m_{11}\left(\mathbf{r}_{11, c 11}-\mathbf{r}_{11, c 12}+\mathbf{r}_{12, c 12}\right) \times \dot{\mathbf{v}}_{c 11} \\
\tau_{r k_{G}}= & -\left\{m_{11}\left(\mathbf{r}_{11, c 11}-\mathbf{r}_{11, c 12}+\mathbf{r}_{12, c 12}\right)+m_{12} \mathbf{r}_{12, c 12}\right\} \times \mathbf{g} \\
\tau_{r k_{G R F}}= & \sum_{k=1}^{n}\left(\mathbf{r}_{1 G R F k} \times \mathbf{f}_{1 G R F k}\right)+\left(\mathbf{n}_{1, c 11}-\mathbf{n}_{1,112}+\mathbf{r}_{2, c 12}\right) \times \sum_{k=1}^{n} \mathbf{f}_{1 G R F k}(8)
\end{aligned}
$$

3.3 支援関節モーメント算出ここでは, 被支 援者を支援するための支援関節モーメントを設計する. 我々は, 筋力の不足により歩行を困難に感じる方々の 筋力を本支援モーメントにより支援する事で, 歩行を はじめとする様々な下肢の運動の支援を目的としてい る. さらに, 支援の結果, 被支援者の行動範囲を含め た行動力が向上する事により, 残存している身体的機 能 (筋力や平衡感覚等) の向上あるいは維持が期待出 来る. しかし, 過度の支援は逆に被支援者の身体的機 能の低下や軍動の妨害を引き起こす可能性がある. そ こで我々は, ある運動を行う際に必要な関節モーメン 
トのうち, 被支援者が自力で発生させることが可能な 分は被支援者が発生させ，不足分を支援モーメントと して補うことで, 装着者の意図した動作の遂行を図る. 膝関節モ一メントは, 立脚期には大腿部や上体部を 支えるために生成され, 逆に遊脚期には下腿部や足部 を支えるために生成されると考えられる. 先に算出し た $\tau_{r k}$ においても, 床反力が立脚期の大腿部や上体部の 運動を反映する事から， $\tau_{r k_{G R F}}$ が主に大腿部や上体部 を支えるために必要な膝関節モーメントを, 残りの項 が下腿部や足部を支えるために生成される膝関節モ一 メントをそれぞれ表していると考えられる.

また， $\tau_{r k_{G R F}}$ は右足に作用する床反力のみに依存し ているため, 遊脚期には 0 となる.このため, 脚の状 態が立脚から遊脚, あるいは遊脚から立脚へと遷移し ても，モデルを切り替えることなく連続して関節モ一 メントの算出が可能である.

さらに, 本研究で支援対象としている高齢者は, 一 般的に動作の速度や加速度がそれほど大きくないため, 重力項が大きな割合をとっている. そのうえ，上半身 の速度や加速度の影響は, 床反力項に含まれているた め, ここでは, 通常の動作において実質影響が少ない $r_{r k_{I}}$ と $r_{r k_{C}}$ を無視し, (5) 式で算出された関節モーメ ントの重力項及び床反力項に基づく支援関節モーメン トを設計する. 例えば右膝関節モーメント $\tau_{r k S}$ は以下 のようになる.

$$
\tau_{r k S}=\alpha_{r k}\left(\tau_{r k_{G}}+\tau_{r k_{G R F}}\right)
$$

このような近似による影響は，走るなどの高速運動 の動作ではない場合, 人間の筋肉が十分吸収できると 考える. このような設計では, 速度や加速度センサが 不要となり, システムの基本構成の低コストへ寄与す るのみではなく,ノイズやドリフト問題に影響が少な いという利点がある。

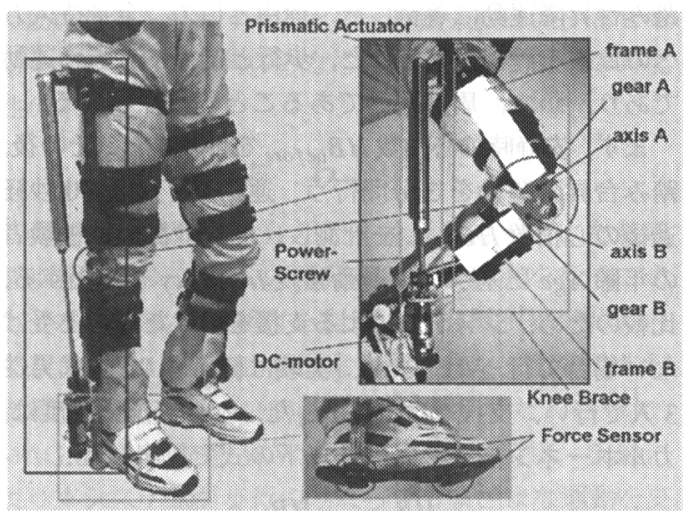

Fig. 3 Wearable Walking Helper-II
また， $\alpha_{r k}$ は支援率とする. 支援率とは算出した $\tau_{r k_{G}}$ および $\tau_{r k_{G R F}}$ のどの程度を支援するかを決定するパラ メータであり, これに比例して $\tau_{r k S}$ は增大する. この 大きさの範囲を $\left(0 \leq \alpha_{r k}<1\right)$ とする事で運動に必要 な関節モーメントの一部を被験者が, 残りを支援関節 モーメントとして支援システムが発生させるという支 援方式が成り立つ。

この必要最低限の補助により, 被支援者の身体機能 の維持あるいは向上が期待される. また,このパラ メータを適切に設定することにより被支援者毎の運動 能力に見合った支援の実現が期待できる.

\section{Wearable Walking Helper-II}

ここでは, 本研究で用いられる装着型脚部筋 力支援デバイス W.W.Helper-II について述べる. W.W.Helper-II は脚部に装着して膝関節周りに支援関 節モーメントを作用するものである. ギア方式デュア ルヒンジと呼ばれる機構を用いた矢状平面上の回転 1 自由度の膝関節部を持つ膝装具, ボールねじと DCモー タからなるバックドライバブルな直動アクチュエータ およびセンサ類から構成されている.

図 3 に開発された W.W.Helper-II を示す. 開発され た W.W.Helper-II は直動アクチュエータで発生した推 力を, 膝装具のフレームに作用し, 膝関節支援モーメ ントを人間の膝関節に伝達する構造となっている. ま た, 床反力計測用に靴底の拇指球および踵に当たる部 分に感圧センサ, 関節角計測用に足関節および膝関節 にポテンショメータを配している.

\section{5. 実験}

ここでは, 提案した MAGMA-GRFを W.W.Helper-II に適用し, 検証実験を行う.ま ず, 支援の連続性について検証し, その後, 運動中の 負担軽隇について検証する.

5.1 歩行速度変化実験 MAGMA-GRFにより 算出された支援関節モーメントが歩行中の脚の状態に 応じて滑らかに生成されているかを検証するために, トレッドミル上を歩行速度を変化させて歩行した. 本 実験では, 歩行速度は時速 $0.8 \mathrm{~km}$ から徐々に加速させ, 時速 $4.0 \mathrm{~km}$ で約 5 秒間一定速度で歩行した後, ふたた び時速 $0.8 \mathrm{~km}$ まで減速した. 被験者は 20 歳代の健常 な男性 1 名で行い, 支援率は 0.4 とした.

図 4 に実験の様子を, 図 5(a) に実験全体を通した膝 関節角度を，(b)に床反力を, また (c) に支援関節モ一 メントをそれぞれ示す. また, 図 6(a)に実験中の歩行 1 周期分の膝関節角度を, (b)に床反力を, また (c) に 支援関節モーメントをそれぞれ示す. 図 5 から歩行速 

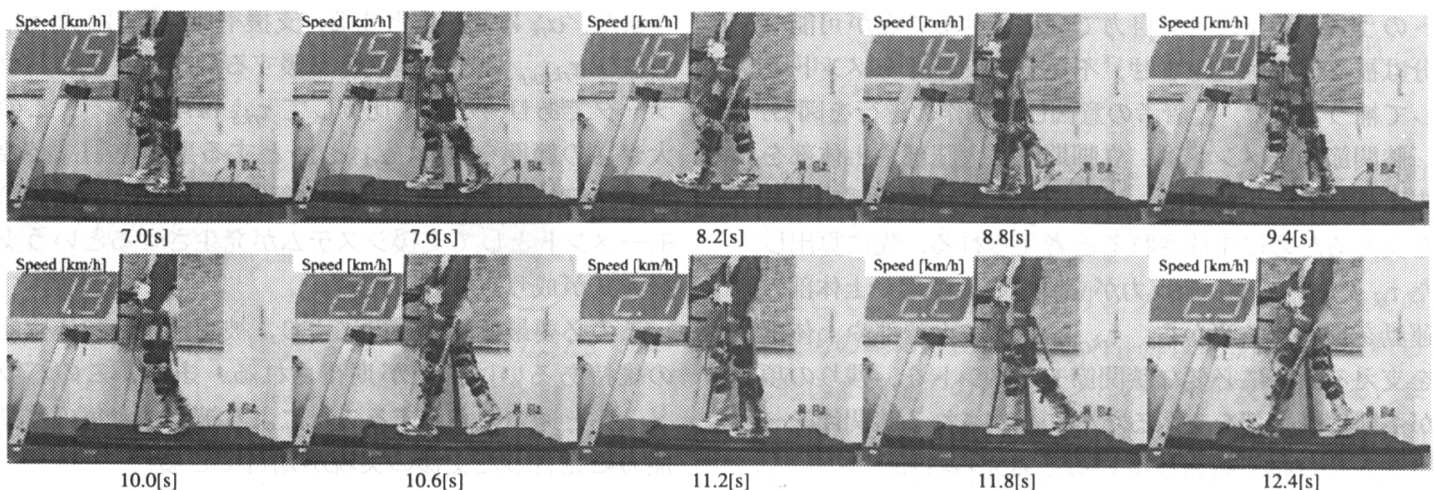

Fig. 4 A Part of Pace-Change Walking
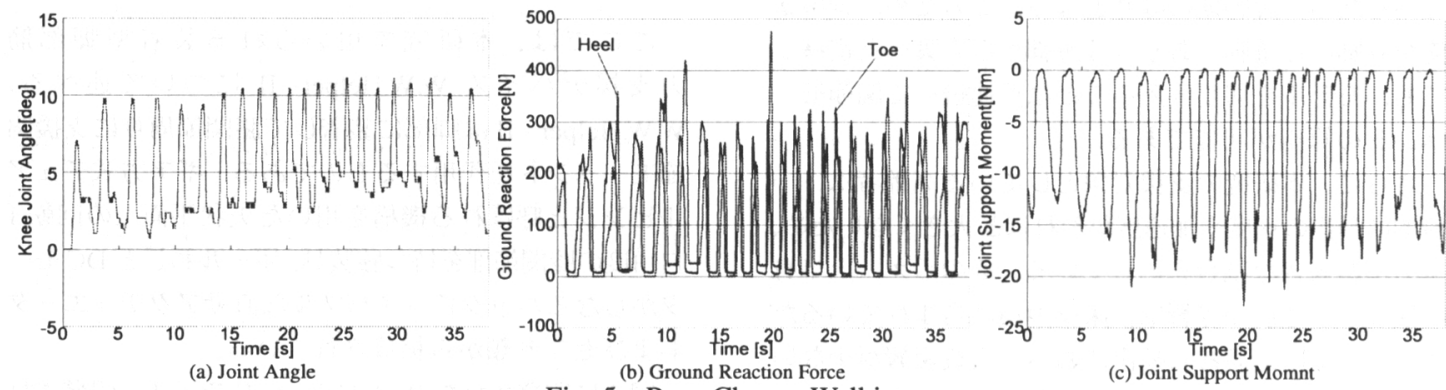

Fig. 5 Pace-Change Walking

(c) Joint Support Momnt

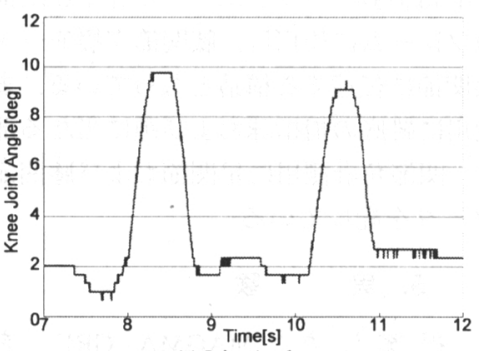

(a) Joint Angle

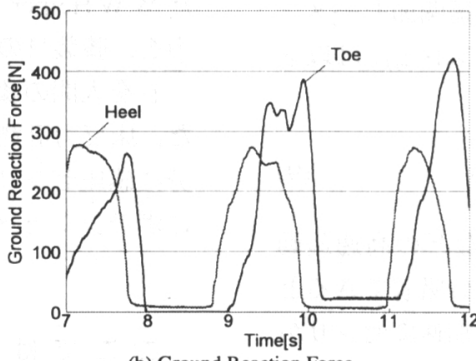

(b) Ground Reaction Force

Fig. 6 A Cycle of Pace-Change Walking

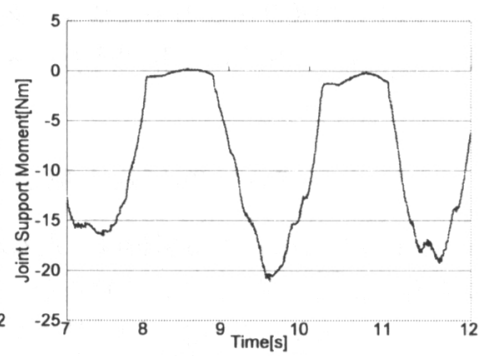

(c) Joint Support Momnt
度の変化に応じてまた, 図 6 から立脚/遊脚に応じて 支援関節モーメントがとぎれること無く連続的に生成 されていることが分かる.

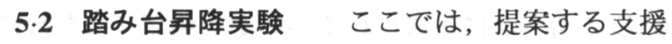
方法により筋への負担を減らすことで，運動による身 体全体への負担（運動強度）にどのような影響を与え るかについて検証する. 肉体の負担を計測する方法と して筋電位計測, 血中乳酸值濃度測定, 心拍数測定等 が考えられる. 筋電位は特定の筋肉の活動状況を知る には有効であるが，身体全体に対する運動の影響を総 合的に評価する場合には，あまり適さない，また，血 中乳酸值濃度の測定には, 被験者の血液が必要となる ため, 専門家による施行が必要となる. 以上を考虑し, 本稿では, 被験者に負担をかけずに運動強度を把握で
きる心拍数を用いる. また, 検証実験用の運動として, 踏み台昇降運動に着目した. 理由として, 全身持久力 への負担を評価出来ること, 歩行と同様に有酸素運動 であり, かつ, 周期運動であることが挙げられる.

まず, 安静時の心拍数 $H B_{\text {before }}$ を計測する. その後, 踏み台昇降運動を 3 分間行う。運動終了から 30 秒経 過後の心拍数 $H B_{\text {after }}$ を計測し，その計測值と被験者 の年齢 Age に基づいて運動強度 Intensity 算出する. 比較のため, システムによる支援を受けた場合と受け ない場合で行った. また, 実験は健常な 20 歳代男性 3 人で行い，支援率は 0.4 とした. なお，運動強度は， カルボーネン法を参考に, 以下の式で算出した.

$$
\text { Intensity }=\frac{H B_{\text {after }}-H B_{\text {before }}}{H B_{\text {Max }}-H B_{\text {before }}} \times 100(\%)
$$




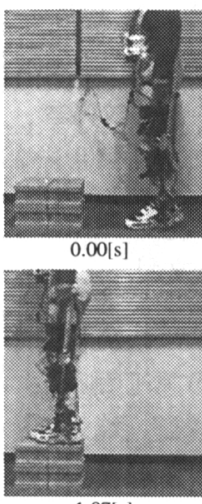

$1.87[\mathrm{~s}]$

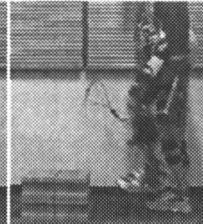

$0.27[s]$

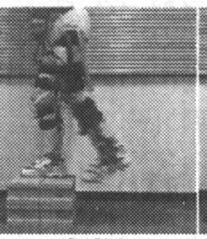

$2.13[s]$

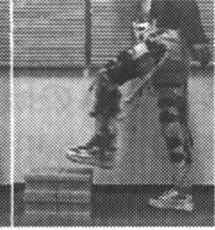

$0.53[\mathrm{~s}]$

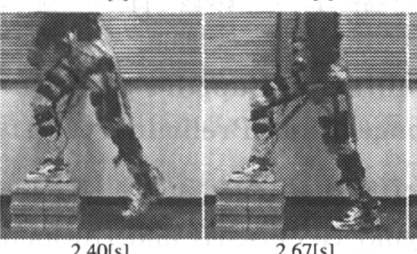

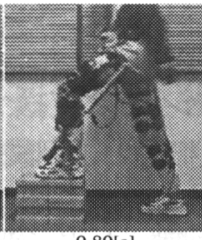

$0.80[s]$

$2.67[s]$

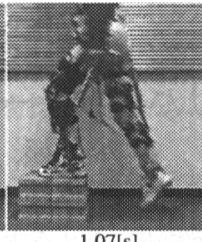

$1.07[\mathrm{~s}]$
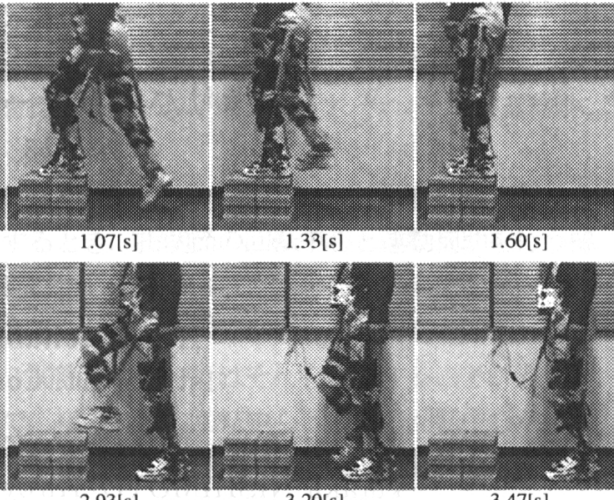

2.93[s]

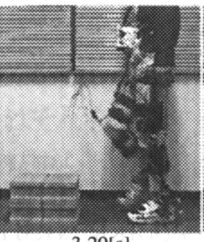

$3.20[\mathrm{~s}]$

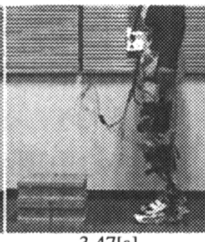

$3.47[s]$

Fig. 7 A Cycle of Step Climbing Up and Down Exercise

Table 1 Heart Beat Rate of Step Climbing Up and Down Experiment

\begin{tabular}{|c||c|c|c|c|}
\hline Subject & Condition & Before & After & Intensity \\
\hline \hline \multirow{2}{*}{$\begin{array}{c}\text { Subject } A \\
\text { (Age 28) }\end{array}$} & Without Support & 83 & 138 & $50.5 \%$ \\
\cline { 2 - 5 } & With Support & 85 & 125 & $37.4 \%$ \\
\hline \multirow{2}{*}{$\begin{array}{c}\text { Subject B } \\
\text { (Age 21) }\end{array}$} & Without Support & 94 & 173 & $75.2 \%$ \\
\cline { 2 - 5 } $\begin{array}{c}\text { Subject } C \\
\text { (Age 24) }\end{array}$ & With Support & 94 & 160 & $62.9 \%$ \\
\cline { 2 - 5 } & With Support & 90 & 117 & $25.5 \%$ \\
\hline
\end{tabular}

$$
H B_{\text {Max }}=220-\text { Age }
$$

図 7 に実験中の動作 1 周期の様子を, 表 1 に心拍数 および算出した運動強度を示す. 表 1 より明らかなよ うに，本支援システムによる支援により，本実験の場 合, 運動強度が平均して $11.4 \%$ 滅少した。これは本実 験と同じペースで 1 階から 5 階まで階段を昇る際, 本 システムによる支援を受けた場合，1階から３階まで 階段を昇るのと同程度の体への負担で実現出来ること を表している. 以上より，本支援システムにより脚部 の筋の負担を軽減することで, 運動強度を減少させる 効果が示され, 歩行のみならず様々な運動支援の可能 性が示唆された。

\section{6.おわりに}

著者らは, 筋力の衰えた高齢者を対象とした装着 型歩行支援システムの開発を目指し研究を行ってき た。本稿では, 床反力を利用した支援制御アルゴリ ズム MAGMA-GRF を提案した。 また, 装着型歩行 支援デバイス W.W.Helper-II を開発した。さらに, MAGMA-GRF を W.W.Helper-II に適用し, 実験に より本システムが歩行のみならずさまざまな運動を支 援できる可能性があることを示した.
これまで，健常者を被験者とした実験により本シス テムの運動支援に対する有效性を示してきた．今後， より実用的なシステムの開発を目指し, 高齢者の運動 支援に重点を置いた検証実験を行うとともに, 支援率 $\alpha$ の決定方法についても検討を行う.

\section{文献}

(1) T. NAKAMURA at el., "Model-Based Wearable Antigravity Muscles Support System for Leg," Trans. of the JSME(C), Vol. 71, No. 702, pp. 618-623, 2005.

(2) B.J. Makinson, General Electric Co., "Research and Development Prototype for Machine Augmentation of Human Strength and Endurance, Hardiman I Project," General Electric Report, S-71-1056, 1971.

(3) H. Kazerooni, J. Guo, "Human Extenders," ASME J. of Dynamic Systems, Measurements, and Control, vol. 115, no. 2(B), June 1993.

(4) Berkley Robotics Laboratory, "Berkeley Exoskeleton (BLEEX)", http://bleex.me.berkeley.edu/bleex.htm

(5) K. YAMAMOTO at el., "Development of Power Assisting Suit for Assisting Nurse Labor," Trans. of the JSME(C), Vol. 67, No. 657, pp. 1499-1506, 2001.

(6) K. Naruse et al., "Three-dimensional Lifting-up Motion Analysis for Wearable Power Assist Device of Lower Back Support," Proc. the IEEE/RSJ Inter'l. Conf. on Intellgent Robots and Systems, pp. 2283-2288, 2005.

(7) T. Hayashi et al., "Control Method of Robot Suit HAL working as Operator's Muscle using Biological and Dynamical Information," Proc. of the IEEE/RSJ Inter'l. Conf. on Inteligent Robotos and Systems, pp. 3455-3460, 2005.

(8) K. Kiguchi et al., "A 3DOF Exoskelton for Upper-Limb Motion Assist -Consideration of the Effect of $\mathrm{Bi}$-Articular Muscles," Proc. of IEEE Inter'l Conf. on Robotics and Automation, pp. 2424-2429, 2004.

(9) V. Zatsiorsky, "The Mass and Inertia Characteristics of the Main Segments of the Human Body," Biomechanics V-IIIB, pp. 1152-1159, 1983.

(10) Christopher L.Vaughan, "Closed Loop Ploblem in Biomechanics," Journal of Biomechanics, Vol. 15, No. 3, pp. 197-200, 1982. 